\title{
Hemogram index parameters in the evaluation of male breast cancer and inflammatory response: a case-control study
}

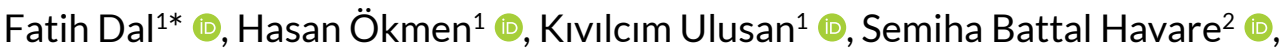

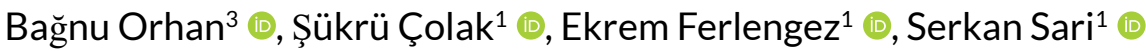

\section{SUMMARY}

OBJECTIVE: Our aim was to investigate the hemogram index parameters and their clinical significance in the evaluation of the inflammatory response of patients with male breast cancer, who are rarely observed in the literature.

METHODS: In total, 22 ( $n=22)$ healthy male and $28(n=28)$ male breast cancer patients without synchronous/metachronous tumors were included in this study. They were grouped as the healthy male control group (Group 1) and the male breast cancer patient group (Group 2). The male breast cancer was divided into two subgroups, namely, early stage [(stage: O/I/II) (Group 2A)] and late stage [(stage: III/IV) (Group 2B)], and their hemogram index parameters were compared.

RESULTS: A significant ( $p>0.05$ ) increase was observed in neutrophil/lymphocyte ratio (NLR) and.platelet/lymphocyte ratio (PLR) values in the late stage (Group 2B: stage III/IV) compared to the early stage (Group 2A: stage O/I/II) and healthy control (Group 1) groups.

CONCLUSIONS: In male breast cancer patients, neutrophil/lymphocyte ratio and platelet/lymphocyte ratio values were significantly higher as the stage of cancer increased. These readily available simple tests can be used to evaluate the host's inflammatory response in male breast cancer. KEYWORDS: Male breast cancer. Neutrophil. Platelet. Lymphocyte. Monocyte.

\section{INTRODUCTION}

Male breast cancer (MBC) is a rare disease accounting for approximately $0.5 \%$ of all cancer cases in the United States and $0.8 \%$ in Turkey ${ }^{1,2}$. Increasing evidence has recently shown that not only the tumor characteristics but also the inflammatory response of the host are effective in the development, progression, and prognosis of neoplastic diseases, including female breast cancers (FBCs) ${ }^{3}$. Although liquid biopsies (such as circulating tumor cells, circulating DNA, circulating miRNA, circulating lncRNA, and exosome) have been developed in the evaluation of treatment response and prognosis in patients with breast cancer, their use is limited due to their high $\operatorname{cost}^{4,5}$.

In this study, we aimed to investigate the low-cost hemogram index parameters (HIPs) and their clinical importance in the evaluation of the inflammatory response of MBC patients, who are rarely seen in the literature.

\section{METHODS}

\section{Ethical approval}

Local ethics committee approval (dated: August 13, 2021, decision no.: 2902) was obtained.

\section{Selection of patients}

Within the scope of the study, the files of $34 \mathrm{MBC}$ patients with code C50 who stayed in the hospital between March 1, 2006, and March 1, 2020, were reviewed retrospectively.

Notably, $28(n=28)$ primary MBC patients without synchronous/metachronous tumors were included in this study. The control group consisted of $22(\mathrm{n}=22)$ healthy men over the age of 18 years who had normal breast examination and breast ultrasonography results, had normal HIP values, and were matched with MBC patient groups in terms of age and gender.

\footnotetext{
${ }^{1}$ Ministry of health, Istanbul Training and Research Hospital, Department of General Surgery - Istanbul, Turkey.

2Ministry of health, Istanbul Training and Research Hospital, Department of Medical Pathology - Istanbul, Turkey.

${ }^{3}$ Ministry of health, Istanbul Training and Research Hospital, Department of Medical Biochemistry - Istanbul, Turkey.

*Corresponding author: fatihdal07@gmail.com

Conflicts of interest: the authors declare there is no conflicts of interest. Funding: none.

Received on September 08, 2021. Accepted on September 16, 2021.
} 
A total of six patients with synchronous/metachronous tumors were excluded from this study. Five of the MBC patients who were excluded from this study were in the early stage, and one was metastatic. The patients' estrogen receptor (ER) and progesterone receptor (PR) were positive. Human epidermal growth factor receptor 2 (HER2) was positive in a patient with early-stage MBC. The histopathological examination revealed invasive ductal cancer (IDC) in five patients and invasive papillary cancer in one patient.

\section{Hemogram index parameters and study design}

The patients' HIP [absolute leukocyte count, i.e., white blood cells (WBC), absolute neutrophil count (ANC), absolute lymphocyte count (ALC), absolute monocyte count (AMC), absolute platelet count (APC), absolute neutrophil count/absolute lymphocyte count ratio (NLR), absolute neutrophil count/absolute monocyte count ratio (NMR), absolute platelet count/absolute lymphocyte count ratio (PLR), absolute lymphocyte count/ absolute monocyte count ratio (LMR), mean platelet volume (MPV), and red blood cell distribution width (RDW)] values, histopathological data, and disease staging were recorded at the time of diagnosis. The groups were divided into two groups, namely, the healthy control group (Group 1) and the MBC group (Group 2). MBC patients were divided into subgroups as Group 2A (stage 0/I/II) and Group 2B (stage III/IV), and their HIP values were compared by the XN $9000^{\circledR}$ (Sysmex, Kobe, Japan) device ${ }^{5-7}$.

\section{Statistical Methods}

Mean, standard deviation, median, minimum-maximum value frequency, and percentage were used for descriptive statistics. The distribution of variables was checked with the Kolmogorov-Smirnov test. The independent samples $t$ test and Mann-Whitney $U$ test were used for the comparison of quantitative data. The $\chi^{2}$ test was used for the comparison of qualitative data. The SPSS software version 27.0 was used for statistical analyses.

\section{RESULTS}

The most common symptom at admission in the MBC patients included in this study was a mass with $89.3 \%$. Of the patients, $85.8 \%$ underwent surgery. Of the patients undergoing surgery, $64.3 \%$ underwent mastectomy + axillary lymph node dissection (MRM or modified radical mastectomy), $17.9 \%$ underwent mastectomy + sentinel lymph node biopsy (MSLNB), 3.6\% underwent palliative mastectomy (PM), and $14.2 \%$ underwent diagnostic tru-cut biopsy
$(\mathrm{Bx})$. In the histological examination, $64.3 \%$ were grade (G) 2, and lymphovascular invasion (LVI) was positive in 53.6\%. The most common histological type was IDC. Of the patients, 92.9\% had ER+, 78.6\% PR+, 71.4\% HER2tumors, and $50 \%$ were in stages III and IV at the time of diagnosis (Table 1).

The mean age of Group 1 (control) and Group 2 (MBC) were $61.0 \pm 8.3$ and $60.6 \pm 10.6$ years, respectively. The mean age of Group 2A (stage: 0/I/II) and Group 2B (stage: III/IV) were $63.1 \pm 11.5$ and $60.1 \pm 13.9$ years, respectively. No significant difference ( $p>0.05)$ was found between the main groups and subgroups in terms of age and gender distribution of the patients. When comparing the HIPs, no significant difference ( $p>0.05)$ was observed in the values of WBC, ANC, ALC, AMC, APC, RDW, PDW, and MPV (Tables 2 and 3).

When comparing the healthy control group (Group 1) and the MBC group, no significant difference ( $p>0.05)$ was observed between the HIP values. NLR and PLR values increased significantly ( $>0.05)$ in the late (Group 2B: stage III/IV) disease stage compared to the early stage (Group 2A: stage 0/I/II) and healthy control (Group 1) groups. Although the LMR value was significantly lower $(\mathrm{p}<0.05)$ in the latestage (Group 2B: stage III/IV) patients compared to the healthy control group (Group 1), there was a noticeable decrease (Group 2A: $4.29 \pm 1.67$ versus Group 2B: $2.75 \pm 1.53$ ), which had no significant relationship $(\mathrm{p}>0.05)$ with disease staging. There was no significant difference $(p>0.05)$ between the healthy control group (Group 1) and the early-stage (Group 2A: 0/I/II) patients group (Table 3).

\section{DISCUSSION}

The incidence of MBC represents less than $1 \%$ of breast cancers worldwide ${ }^{1,2,8}$. A mass in the breast, observed in $75-81 \%$ of patients, is the most common symptom. MBC patients are at later stages (stage III/IV) compared to FBC patients at the time of the diagnosis ${ }^{9,10}$. The incidence of stage III/IV cancer at admission is $>60 \%$ in Africa, $<40 \%$ in North America and Western European countries, and between $40 \%$ and $60 \%$ in Eastern Europe and South America. The reasons for admission at later stages are reported to be race, low socioeconomic status, lack of awareness about the disease, and uncertainties in the characterization of high-risk patients for screening in the literature ${ }^{8,11-17}$. In our study, the most common symptom was a breast mass, and $50 \%$ of them were at late stages at the time of diagnosis. Our results were better than the data available in the African literature and worse than those in developed countries. 
Table 1. Distribution of clinicopathological data of male breast cancer patients

\begin{tabular}{|c|c|c|c|}
\hline & & $n$ & $\%$ \\
\hline \multirow{2}{*}{ Symptoms } & Mass & 25 & 89.3 \\
\hline & Mass and ulcerated & 3 & 10.7 \\
\hline \multirow{4}{*}{$\begin{array}{l}\text { Surgery or } \\
\text { diagnosis }\end{array}$} & MRM & 18 & 64.3 \\
\hline & Mastectomy+SLNB & 5 & 17.9 \\
\hline & Palliative mastectomy & 1 & 3.6 \\
\hline & Biopsy & 4 & 14.2 \\
\hline \multirow{4}{*}{ Histological type } & DCIS & 1 & 3.6 \\
\hline & IDC & 21 & 74.0 \\
\hline & Mix type & 5 & 17.8 \\
\hline & Special type & 1 & 3.6 \\
\hline \multirow{5}{*}{$\begin{array}{l}\text { Tumor size } \\
\text { category }\end{array}$} & pTis & 1 & 3.6 \\
\hline & pT1 & 8 & 28.6 \\
\hline & pT2 & 9 & 32.1 \\
\hline & pT3 & 0 & 0.0 \\
\hline & pT4 & 10 & 35.7 \\
\hline \multirow{4}{*}{$\begin{array}{l}\text { Nodal category } \\
(\mathrm{N})\end{array}$} & pNO & 10 & 35.7 \\
\hline & $\mathrm{pN1}$ & 10 & 35.7 \\
\hline & $\mathrm{pN} 2$ & 6 & 21.4 \\
\hline & pN3 & 2 & 7.2 \\
\hline \multirow{2}{*}{ Nodal status } & Yes & 18 & 64.3 \\
\hline & No & 10 & 35.7 \\
\hline \multirow{2}{*}{ Metastasis (M) } & M1 & 6 & 21.4 \\
\hline & $\mathrm{MO}$ & 22 & 78.6 \\
\hline \multirow{5}{*}{ Stage } & Stage 0 & 1 & 3.6 \\
\hline & Stage I & 5 & 17.8 \\
\hline & Stage II & 8 & 28.6 \\
\hline & Stage III & 8 & 28.6 \\
\hline & Stage IV & 6 & 21.4 \\
\hline \multirow{4}{*}{ Grade (G) } & G1 & 0 & 0.0 \\
\hline & G2 & 18 & 64.3 \\
\hline & G3 & 6 & 21.4 \\
\hline & Missing & 4 & 14.3 \\
\hline \multirow{3}{*}{ ER status } & $E R<1$ & 1 & 3.6 \\
\hline & $E R \geq 1$ & 26 & 92.8 \\
\hline & Missing & 1 & 3.6 \\
\hline \multirow{3}{*}{ PR status } & $\mathrm{PR}<1$ & 5 & 17.8 \\
\hline & $P R \geq 1$ & 22 & 78.6 \\
\hline & Missing & 1 & 3.6 \\
\hline \multirow{3}{*}{ HER2 status } & Yes & 4 & 14.3 \\
\hline & No & 20 & 71.4 \\
\hline & Missing & 4 & 14.3 \\
\hline \multirow{3}{*}{$\begin{array}{l}\text { Lymphovascular } \\
\text { invasion }\end{array}$} & Yes & 15 & 53.6 \\
\hline & No & 4 & 14.3 \\
\hline & Missing & 9 & 32.1 \\
\hline
\end{tabular}

MRM: modified radical mastectomy; SLNB: sentinel lymph node biopsy; DCIS: ductal carcinoma in situ; IDC: invasive ductal cancer; T: tumor size; N: nodal category; M: metastasis; ER: estrogen receptor; PR: progesterone receptor; HER 2: human epithelial growth factor receptor-2.
There is a need for regional studies to reveal the reasons for the late admission of patients.

In the African literature, $61.5-88.9 \%$ and $46.5 \%$ of patients in developed countries have axillary lymph node metastases at the time of diagnosis ${ }^{11,12,14}$. Although breast-conserving surgery and SLNB are alternative options in the treatment of early-stage (stage 0/I/II) MBC, MRM is still the standard surgical treatment method in recent days ${ }^{11,14,18,19}$. In locally advanced (stage III) MBC, staged surgical mastectomy can be performed after preoperative systemic chemotherapy (10). Patients with metastatic (stage IV) MBC are younger ( $\leq 65$ years old), those with T1 tumors or those who have undergone surgical mastectomy have better survival rates than those who have not undergone a surgical intervention ${ }^{20}$. According to the immunohistochemical evaluation of the patients, $83-96 \%$ had ER+, 81-96\% had PR+, and 10.6-35.1\% were HER2 positive, and the most common histological type was IDC, which was observed in $80-90 \%$ of the patients ${ }^{13,15,17}$. More than half of these patients had LVI, and the predominant histological grade was $\mathrm{G}^{8-13,15,17}$. In terms of histopathological evaluation and surgical treatment, our results are in accordance with the literature.

In breast cancers, males and females have similar prognostic factors. The main prognostic factors associated with disease-related survival are as follows: G, stage, hormone receptor status, tumor size, and lymph node status ${ }^{21}$. Recent studies on FBC have shown that patient-related inflammatory factors play a role in tumor initiation, formation, development, recurrence, metastasis, and treatment response. High NLR, PLR, and low LMR are reported as prognostic factors associated with survival $^{3,22,23}$. In the study by Sun et al. comparing HIP values of healthy and FBC patients, MPV, RDW, NLR, and PLR values were found higher in FBC patients ${ }^{6}$. In a similar study, Rana et al. observed a decrease in the mean lymphocyte count as the stage of FBC patients increased ${ }^{7}$. In their study conducted on patients with metastatic FBC, Lee et al. reported that overall survival was shorter in patients with low $\mathrm{ALC}^{24}$. This is related to the decrease in the number of CD8+ T lymphocytes, which is the basic mechanism of tumor immunity, or the suppression of T-lymphocyte activity by neutrophils, which develop secondary to the increase in interleukin- 8 secreted from the tumor. In addition, tumor angiogenesis and stroma formation are supported by the effect of vascular endothelial growth factor secreted from platelets ${ }^{6,23}$. It is reported that these easily accessible parameters may be useful in the management of FBC patients. However, due to the lack of studies on MBC and HIP in the literature, our knowledge is based on the data of WBC patients. 
Table 2. Comparison of hemogram index parameters between control group and breast cancers.

\begin{tabular}{|c|c|c|c|c|c|c|c|}
\hline \multirow[b]{3}{*}{ Male } & \multicolumn{3}{|c|}{ Group 1 (control) } & \multicolumn{3}{|c|}{ Group 2 (stage 0/I/II/III/IV) } & \multirow{3}{*}{$\begin{array}{l}\text { p-value } \\
1.000^{\times 2}\end{array}$} \\
\hline & \multirow[t]{2}{*}{ Median } & \multicolumn{2}{|c|}{ Mean $\pm S D / n(\%)$} & \multirow[t]{2}{*}{ Median } & \multicolumn{2}{|c|}{ Mean士SD/n (\%) } & \\
\hline & & 22 & 100 & & 28 & 100 & \\
\hline Age & 59.5 & \multicolumn{2}{|c|}{$61.0 \pm 8.3$} & 60.0 & \multicolumn{2}{|c|}{$60.6 \pm 10.6$} & $0.399^{m}$ \\
\hline WBC (×10\%/L) & 7.50 & \multicolumn{2}{|c|}{$7.65 \pm 1.42$} & 7.08 & \multicolumn{2}{|c|}{$8.08 \pm 2.63$} & $0.953^{m}$ \\
\hline Neutrophil $\left(\times 10^{9} / \mathrm{L}\right)$ & 4.28 & \multicolumn{2}{|c|}{$4.45 \pm 0.79$} & 4.29 & \multicolumn{2}{|c|}{$4.89 \pm 2.58$} & $0.845^{m}$ \\
\hline Lymphocyte (×10\%/L) & 2.38 & \multicolumn{2}{|c|}{$2.37 \pm 0.89$} & 2.15 & \multicolumn{2}{|c|}{$2.07 \pm 0.57$} & $0.115^{t}$ \\
\hline Monocyte (×10\%/L) & 0.57 & \multicolumn{2}{|c|}{$0.59 \pm 0.19$} & 0.60 & \multicolumn{2}{|c|}{$0.89 \pm 1.02$} & $0.551^{\mathrm{m}}$ \\
\hline Platelet $\left(\times 10^{9} / L\right)$ & 234.0 & \multicolumn{2}{|c|}{$238.4 \pm 64.0$} & 225.5 & \multicolumn{2}{|c|}{$246.4 \pm 86.0$} & $0.718^{t}$ \\
\hline RDW & 13.3 & \multicolumn{2}{|c|}{$14.0 \pm 1.8$} & 13.9 & \multicolumn{2}{|c|}{$14.1 \pm 1.2$} & $0.197^{m}$ \\
\hline PDW & 16.0 & \multicolumn{2}{|c|}{$21.2 \pm 14.4$} & 15.7 & \multicolumn{2}{|c|}{$19.6 \pm 13.1$} & $0.314^{m}$ \\
\hline$M P \vee(f L)$ & 8.90 & \multicolumn{2}{|c|}{$9.31 \pm 1.81$} & 9.40 & \multicolumn{2}{|c|}{$9.34 \pm 1.33$} & $0.660^{t}$ \\
\hline NLR & 1.95 & \multicolumn{2}{|c|}{$2.39 \pm 2.18$} & 2.19 & \multicolumn{2}{|c|}{$2.72 \pm 2.26$} & $0.423^{m}$ \\
\hline PLR & 101.2 & \multicolumn{2}{|c|}{$103.7 \pm 45.1$} & 108.9 & \multicolumn{2}{|c|}{$127.5 \pm 53.8$} & $0.123^{m}$ \\
\hline LMR & 4.02 & \multicolumn{2}{|c|}{$4.54 \pm 2.35$} & 3.54 & \multicolumn{2}{|c|}{$3.52 \pm 1.76$} & $0.171^{t}$ \\
\hline
\end{tabular}

SD:Standard deviation; WBC: white blood cells (×109/L); RDW: red blood cell distribution width (\%); PDW: platelet distribution width (\%); MPV: mean platelet volume (fL); NLR: neutrophil-to-lymphocyte ratio; PLR: platelet-to-lymphocyte ratio; LMR: Iymphocyte-to-monocyte ratio. ${ }^{\mathrm{t} t}$ test; ${ }^{\mathrm{m} M a n n-W h i t n e y ~} \mathrm{U}$ test; ${ }^{2}{ }^{2}{ }^{2}$ (Fisher's exact test).

Table 3. Comparison of hemogram index parameters between control group and subgroup breast cancers.

\begin{tabular}{|c|c|c|c|c|c|c|c|c|c|c|}
\hline \multirow[b]{3}{*}{ Male } & \multicolumn{3}{|c|}{ Group 1 (control) } & \multicolumn{3}{|c|}{ Group 2A (stage 0/I/II) } & \multicolumn{3}{|c|}{ Group 2B (stage III/IV) } & \multirow{3}{*}{$\begin{array}{c}\mathbf{p} \\
1.000^{\times 2}\end{array}$} \\
\hline & \multirow[t]{2}{*}{ Median } & \multicolumn{2}{|c|}{ Mean \pm SD/n (\%) } & \multirow[t]{2}{*}{ Median } & \multicolumn{2}{|c|}{ Mean \pm SD/n (\%) } & \multirow{2}{*}{ Median } & \multicolumn{2}{|c|}{ Mean \pm SD/n (\%) } & \\
\hline & & 22 & 100 & & 14 & 100 & & 14 & 100 & \\
\hline Age & 59.5 & \multicolumn{2}{|c|}{$61.0 \pm 8.3$} & 67.0 & \multicolumn{2}{|c|}{$63.1 \pm 11.5$} & 63.5 & \multicolumn{2}{|c|}{$60.1 \pm 13.9$} & $0.757^{A}$ \\
\hline WBC $\left(\times 10^{9} / \mathrm{L}\right)$ & 7.50 & \multicolumn{2}{|c|}{$7.65 \pm 1.42$} & 6.80 & \multicolumn{2}{|c|}{$7.43 \pm 2.10$} & 8.18 & \multicolumn{2}{|c|}{$8.73 \pm 3.01$} & $0.354^{k}$ \\
\hline Neutrophil $\left(\times 10^{9} / \mathrm{L}\right)$ & 4.28 & \multicolumn{2}{|c|}{$4.45 \pm 0.79$} & 3.73 & \multicolumn{2}{|c|}{$4.14 \pm 2.12$} & 4.75 & \multicolumn{2}{|c|}{$5.63 \pm 2.85$} & $0.298^{\mathrm{k}}$ \\
\hline $\begin{array}{l}\text { Lymphocyte } \\
\left(\times 10^{9} / L\right)\end{array}$ & 2.38 & \multicolumn{2}{|c|}{$2.37 \pm 0.89$} & 2.25 & \multicolumn{2}{|c|}{$2.30 \pm 0.47$} & 1.96 & \multicolumn{2}{|c|}{$1.84 \pm 0.57$} & $0.890^{\mathrm{A}}$ \\
\hline Monocyte (×109/L) & 0.57 & \multicolumn{2}{|c|}{$0.59 \pm 0.19$} & 0.52 & \multicolumn{2}{|c|}{$0.79 \pm 1.01$} & 0.67 & \multicolumn{2}{|c|}{$0.98 \pm 1.06$} & $0.204^{k}$ \\
\hline Platelet $\left(\times 10^{9} / \mathrm{L}\right)$ & 234.0 & \multicolumn{2}{|c|}{$238.4 \pm 64.0$} & 220.5 & \multicolumn{2}{|c|}{$240.7 \pm 103.3$} & 228.5 & \multicolumn{2}{|c|}{$252.1 \pm 67.9$} & $0.870^{A}$ \\
\hline RDW (\%) & 13.3 & \multicolumn{2}{|c|}{$14.0 \pm 1.8$} & 13.8 & \multicolumn{2}{|c|}{$13.8 \pm 0.9$} & 14.0 & \multicolumn{2}{|c|}{$14.4 \pm 1.4$} & $0.157^{k}$ \\
\hline PDW (\%) & 16.0 & \multicolumn{2}{|c|}{$21.2 \pm 14.4$} & 14.5 & \multicolumn{2}{|c|}{$15.8 \pm 8.8$} & 16.2 & \multicolumn{2}{|c|}{$23.4 \pm 15.7$} & $0.196^{k}$ \\
\hline MPV (fL) & 8.90 & \multicolumn{2}{|c|}{$9.31 \pm 1.81$} & 9.40 & & .15 & 9.25 & & .47 & $0.554^{\mathrm{A}}$ \\
\hline NLR & 1.95 & & $18^{*}$ & 1.48 & & $.93^{*}$ & 2.78 & & 2.84 & $0.034^{k}$ \\
\hline PLR & 101.2 & & $5.1^{*}$ & 97.5 & & 38.9* & 131.0 & & 58.9 & $0.023^{K}$ \\
\hline LMR & 4.02 & & $35^{*}$ & 4.36 & & .67 & 2.49 & & .53 & $0.030^{\mathrm{A}}$ \\
\hline
\end{tabular}

SD: Standard deviation; WBC: white blood cells (×109/L); RDW: red blood cell distribution width (\%); PDW: platelet distribution width (\%); MPV: mean platelet volume (fL); NLR: neutrophil-to-lymphocyte ratio; PLR: platelet-to-lymphocyte ratio; LMR: Iymphocyte-to-monocyte ratio. Bold values denote statistical significance at $\mathrm{p}<0.05 .{ }^{\mathrm{A}}$ Analysis of variance; ${ }^{K}$ Kruskal-Wallis (Mann-Whitney $U$ test); ${ }^{2} \chi^{2}$ (Fisher's test); ${ }^{*}$ Difference with Group 2B (stage III/IV).

In the literature, the only up-to-date publication on MBC patients and HIP belongs to Huszno et al., who reported that high PLR, NLR, and MLR values are associated with low overall survival in MBC patients ${ }^{25}$. In our study, as the
MBC patients' disease stage increased, their NLR and PLR values also increased significantly $(\mathrm{p}<0.05)$ while a noticeable but nonsignificant $(p>0.05)$ decrease was observed in LMR mean values (Group 2A: $4.29 \pm 1.67$ versus Group 2B: 
$2.75 \pm 1.53)$. There was no significant $(p>0.05)$ difference between the healthy control group and the MBC group. This was because it was affected by MBC patients at the early stage (Group 2A: 0/I/II). Our results are in accordance with the existing literature.

The main limitation to our study is that a survival study could not be conducted due to its retrospective design, the rarity of MBC patients, and its limited sample size. However, we believed that our results would provide some perspectives for prospective larger-scale studies.

\section{CONCLUSION}

As the disease stage increased in MBC, NLR and PLR values also increased significantly higher. These readily available simple tests can be used to evaluate the host's inflammatory response to $\mathrm{MBC}$.

\section{REFERENCES}

1. Siegel RL, Miller KD, Jemal A. Cancer Statistics, 2017. CA Cancer J Clin. 2017;67(1):7-30. https://doi.org/10.3322/caac.213872

2. Șencan I, Keskinkiliç B, editors. Türkiye kanser istatistikleri. Ankara: T.C. Sağlık Bakanlığı Türkiye Halk Sağlığı Kurumu; 2017.

3. Chen L, Kong X, Yan C, Fang Y, Wang J. The research progress on the prognostic value of the common hematological parameters in peripheral venous blood in breast cancer. Onco Targets Ther. 2020;13:1397-412. https://doi.org/10.2147/OTT.S227171

4. Amorim M,SaltaS, Henrique R, Jerónimo C. Decoding the usefulness of non-coding RNAs as breast cancer markers. J Transl Med. 2016;14:265. https://doi.org/10.1186/s12967-016-1025-3

5. Kuniyoshi RK, Gehrke FS, Alves BC, Vilas-Bôas V, Coló AE, Sousa N, et al. Gene profiling and circulating tumor cells as biomarker to prognostic of patients with locoregional breast cancer. Tumour Biol. 2015;36(10):8075-83. https://doi.org/10.1007/s13277-0153529-5

6. Sun $\mathrm{H}$, Yin CQ, Liu Q, Wang F, Yuan CH. Clinical significance of routine blood test-associated inflammatory index in breast cancer patients. Med Sci Monit. 2017;23:5090-5. https://doi.org/10.12659/ msm.906709

7. Rana AP, Kaur M, Zonunsanga B, Puri A, Kuka AS. Preoperative peripheral blood count in breast carcinoma: predictor of prognosis or a routine test. Int J Breast Cancer. 2015;2015:964392. https:// doi.org/10.1155/2015/964392

8. Uslukaya Ö, Gümüș M, Gümüș H, Bozdağ Z, Türkoğlu A. The management and outcomes of male breast cancer. J Breast Health. 2016;12(4):165-70. https://doi.org/10.5152/tjbh.2016.3073

9. Özkurt E, Tükenmez M, Yılmaz R, Cabioğlu N, Müslümanoğlu M, Dinççağ AS. Favorable long-term outcome in male breast cancer. Eur J Breast Health. 2018;14(3):180-5. https://doi.org/10.5152/ ejbh.2018.3946

10. Fentiman I. Male breast cancer: a review. Ecancermedicalscience. 2009;3:140. https://doi.org/10.3332/ecancer.2009.140

\section{ACKNOWLEDGMENTS}

The authors thank the Health Sciences University Turkish Ministry of Health İstanbul Research and Training Hospital Research Projects Unit.

\section{AUTHORS' CONTRIBUTION}

FD: Conceptualization, Methodology, Writing - original draft, Writing - review \& editing. HÖ: Conceptualization, Formal Analysis, Investigation, Writing - review \& editing. KU: Conceptualization, Formal Analysis, Investigation, Writing - review \& editing. SBH: Methodology, Formal Analysis, Investigation, Writing - review \& editing. BO: Formal Analysis, Methodology, Writing - review \& editing. ŞÇ: Methodology, Formal Analysis, Investigation, Writing - review \& editing. EF: Formal Analysis, Investigation, Writing - review \& editing. SS: Methodology, Writing - original draft, Writing - review \& editing.

11. Zongo N, Ouédraogo S, Korsaga-Somé N, Somé OR, Go N, Ouangré E, et al. Male breast cancer: diagnosis stages, treatment and survival in a country with limited resources (Burkina Faso). World J Surg Oncol. 2018;16(1):4. https://doi.org/10.1186/ s12957-017-1297-y

12. Fouhi ME, Mesfioui A, Benider A. Male breast cancer: a report of 25 cases. Pan Afr Med J. 2020;37:343. https://doi.org/10.11604/ pamj.2020.37.343.23004

13. KonduriS, Singh M, Bobustuc G, Rovin R, Kassam A. Epidemiology of male breast cancer. Breast. 2020;54:8-14.https://doi.org/10.1016/j. breast.2020.08.010

14. Srour MK, Amersi F, Mirocha J, Giuliano AE, Chung A. Male breast cancer: 13-year single institution experience. Am Surg. 2020;86(10):1345-50. https://doi. org/10.1177/0003134820964444

15. Mangone L, Ferrari F, Mancuso P, Carrozzi G, Michiara M, Falcini $F$, et al. Epidemiology and biological characteristics of male breast cancer in Italy. Breast Cancer. 2020;27(4):724-31. https://doi. org/10.1007/s12282-020-01068-1

16. Piciu A, Piciu D, Polocoser N, Kovendi AA, Almasan I, Mester A, et al. Diagnostic performance of F18-FDG PET/CT in male breast cancers patients. Diagnostics (Basel). 2021;11(1):119. https://doi. org/10.3390/diagnostics11010119

17. Spreafico FS, Cardoso-Filho C, Cabello C, Sarian LO, Zeferino LC, Vale DB. Breast cancer in men: clinical and pathological analysis of 817 cases. Am J Mens Health. 2020;14(4):1557988320908109. https://doi.org/10.1177/1557988320908109

18. Elmi M, Sequeira S, Azin A, Elnahas A, McCready DR, Cil TD. Evolving surgical treatment decisions for male breast cancer: an analysis of the National Surgical Quality Improvement Program (NSQIP) database. Breast Cancer Res Treat. 2018;171(2):427-34 https://doi.org/10.1007/s10549-018-4830-y

19. Khan NAJ, Tirona M. An updated review of epidemiology, risk factors, and management of male breast cancer. Med Oncol. 2021;38(4):39. https://doi.org/10.1007/s12032021-01486-x 
20. Chen W, Huang Y, Lewis GD, Szeja SS, Hatch SS, Farach A, et al. Treatment outcomes and prognostic factors in male patients with stage IV breast cancer: a population-based study. Clin Breast Cancer. 2018;18(1):e97-105. https://doi.org/10.1016/j.clbc.2017.07.005

21. Darkeh MHSE, Azavedo E. Male breast cancer clinical features, risk factors, and current diagnostic and therapeutic approaches. Int J Clin Med 2014;5(17):1068-86. https://doi.org/10.4236/ ijcm.2014.517138

22. Liu J, Ma F, Sun B, Cong Y, Xuan L, Wang Q, et al. Predictive value of lymphocyte-related blood parameters at the time point of lymphocyte nadir during radiotherapy in breast cancer. Onco Targets Ther. 2020;13:151-61. https://doi.org/10.2147/OTT. S233244
23. Guo W, Lu X, Liu Q, Zhang T, Li P, Qiao W, et al. Prognostic value of neutrophil-to-lymphocyte ratio and platelet-to-lymphocyte ratio for breast cancer patients: An updated meta-analysis of 17079 individuals. Cancer Med. 2019;8(9):4135-48. https://doi. org/10.1002/cam4.2281

24. Lee YT. Peripheral lymphocyte count and suppopulations of T and B lymphocytes in benign and malignant diseases. Surg Gynecol Obstet. 1977;144(3):435-50. PMID: 300179

25. Huszno J, Kołosza Z, Mrochem-Kwarciak J, Zajusz A. Prognostic value of the neutrophil-lymphocyte, plateletlymphocyte, and monocyte-lymphocyte ratios in male breast cancer patients. Oncology. 2020;98(7):487-92. https://doi. org/10.1159/000505627 